\title{
French reforms would disrupt research
}

Sir - The French scientific community is seriously worried about a furtively proposed government decree on the Centre National de la Recherche Scientifique (CNRS). Claude Allègre, the science minister, has proposed a sweeping reform without consulting the organization's director general, the scientific directors, or the members of its scientific committees.

Even in the best scenario, Allègre's proposal will lead to the break up of the CNRS, effectively ending its involvement in formulating research policy (see Nature 396, 607; 1998). The CNRS would become a funding agency ruled by the short term political aims of the government.

As disturbing is the apparently seductive notion that the break up of the CNRS will bolster French universities by entrusting them with the principal responsibility for scientific research. In this utopian plan, a relatively small number of CNRS researchers would be dispersed among the much larger university population with the aim of 'improving' these institutions. A much more likely outcome will be the dissipation of the research community without significantly affecting the universities. Allègre, fascinated by the US research establishment, seems to forget that French universities, faced with the hard reality of mass teaching, are not elite institutions like the Massachusetts Institute of Technology or Caltech. He also tends to forget that public organizations exist in the United States (the National Institutes of Health), the United Kingdom (Medical Research Council) and Germany (Max Planck Institutes), and that these institutions have an important role in establishing science policy.

Belgium and Italy have experimented with proposals similar to those of Allègre, and we all know how catastrophic this has been. Interference by the state in planning and recruitment has nearly destroyed the research community.

Never before have the CNRS and its researchers been so involved in working with the French universities. As an independent research organization, the CNRS has had a pivotal role in developing regional research centres affiliated to universities. The CNRS would not have been able to do so if it had been integrated into the university system. So it is all the more strange that a project breaking up the CNRS has been proposed now.

Other research organizations such as the biomedical agency INSERM and ORSTOM, the research agency for developing countries, are likely to be next on the list to suffer from the same measures.

Our aim is to convince Allègre that the proposal needs serious reconsideration. This poorly thought out reform is not the solution, because it will inevitably disrupt the research community. French scientists have an important role in reforming the system, and they deserve to be heard.

Alain Bucheton

(President)

Section 23 - Génomes, fonctions et régulations, Comité National de la Recherche Scientifique, CNRS, 3 Rue Michel-Ange, 75794 Paris Cedex 16, France

\section{Lab guidelines aim to prevent misconduct}

Sir - In response to your editorial, "Surviving misconduct is one thing, accountability is another" ${ }^{\text {, }}$, and a subsequent comment ${ }^{2}$, I would like to bring to your notice an initiative already under way to provide "good guidelines for the conduct of research".

In 1993 the Danish Committee on Scientific Dishonesty, appointed by the Danish Medical Research Council, defined guidelines for the presentation of experimental reports, and data documentation and storage. It was felt that, if such proposals were to have a chance of being followed, they had to be concise and readily available in the research milieu. After consultation with all major medical research institutions in Denmark, the revised guidelines were printed on one sheet of paper - those for basic health research on one side, and those for clinical research on the other side. The page was embedded in acid-proof plastic to prevent it from being damaged in the laboratory.

About 1,000 copies were distributed to laboratories all over Denmark. After a year's trial in 1995, new comments were invited from the same institutions. The guidelines had been well received and were being used. On the basis of proposals for improvement, an updated version was distributed to $\mathrm{PhD}$ students and their supervisors, and made available to all interested parties. This revised version was published in English in a paper describing the motives for the choice of guidelines and how they were adapted to medical research in Denmark ${ }^{3}$. The guidelines are also available on the web (http://www.forskraad.dk/publ/guide.html).

I think this preventive initiative is much in keeping with the proposed "adoption of a standardized recording protocol”"

\section{Torben Clausen}

Department of Physiology, University of Aarhus, DK-8000 Århus C., Denmark

1. Nature 395, 727 (1998).

2. Angelides, K. \& Pianelli, J. V. Nature 396, 404 (1998).

3. Clausen, T. \& Riis, P. Dan. Med. Bull. 44, 85-87 (1997).

\section{Did agriculture cause the population explosion?}

Sir - I was pleased to see Thomas Malthus commemorated in Roger Short's

bicentennial essay ${ }^{1}$, but disappointed that agriculture's role in the population explosion was ignored.

The two "major factors" identified by Short (erosion of traditional breastfeeding practices, and conquest of infectious diseases) did surely contribute to the rapid growth of population, but only because they were accompanied by an increase in the food supply. The expansion of agricultural land since Malthus's time, and the enormous increases in crop yields resulting from the application of science to agricultural technology, were what allowed the population to grow to 6 billion. Yields per hectare of several major crops have increased by factors of two to seven in the United States in the past 60 years ${ }^{2}$, and in other countries by similarly large factors ${ }^{3}$.

Malthus's emphasis on food as the limit to population may be confirmed if agricultural productivity soon begins to level off, as many predict ${ }^{3}$.

\section{Stephen G. Warren}

Department of Atmospheric Sciences, University of Washington, Seattle, Washington 98195-1640, USA

Short replies - I do not agree that agricultural improvements have had a major impact on human fertility. Women have to be severely malnourished before fertility is affected ${ }^{4}$. State of nutrition is not normally one of the principal determinants of human fertility; the women in Belsen and in the Dutch famine of the Second World War continued to get pregnant.

However, improvements in agricultural productivity have certainly prevented deaths from starvation in today's overpopulated world, and, as Malthus said, at the end of the day food is necessary to the life of the man. Roger Short

Royal Women's Hospital, 132 Grattan Street, Carlton, Victoria 3053, Australia

1. Short, R. Nature 395, 456 (1998).

2. Warren, G. F. Weed Technology 12 (in the press)

3. Mann, C. Science 277, 1038-1043 (1997).

4. Bongaarts, J. Science 208, 564 (1980). 